\title{
Editorial
}

\section{Missão da Psicopatologia Fundamental}

\author{
Manoel Tosta Berlinck*
}

Com as defesas das dissertações de Laerte Alves de Paula, Tomás Moraes de Abreu Bonomi e Thaís da Silva Pereira, realizadas em 2015, cujos textos completos encontram-se em www.psicopatologiafundamental.org, a Psicopatologia Fundamental comemora 20 anos de existência no Brasil.

Desde de que a invenção de Pierre Fédida, na Université de Paris 7 - Denis Diderot, foi doada ao Brasil em 1994, o Laboratório de Psicopatologia Fundamental do Programa de Estudos Pós-Graduados em Psicologia Clínica da Pontifícia Universidade Católica de São Paulo, criado em 1995, possibilitou a formação de 117 Mestres e Doutores, ou seja, a média de 5,85 profissionais por ano, contribuindo significativamente para o aperfeiçoamento do pessoal do ensino superior.

O Laboratório também contribuiu decisivamente para a criação e manutenção do Congresso Brasileiro de Psicopatologia Fundamental, do Congresso Internacional de Psicopatologia Fundamental, da Associação Universitária de Pesquisa em Psicopatologia Fundamental (AUPPF), da Revista Latinoamericana de Psicopatologia Fundamental, dos portais (sites) www.psicopatologiafundamental.org e www. fundamentalpsychopathology.org, da Plataforma Internacional de Psicopatologia Fundamental e da Newsletter mensal da AUPPF.

Essa instituição particular (não estatal) de aperfeiçoamento e pesquisa foi criada e se sustenta para atender uma aposta e um desafio.

\footnotetext{
* Pontifícia Universidade Católica de São Paulo - PUC-SP (São Paulo, SP, Br).
} 
Não era - como ainda não é - possível restringir a formação de clínicos que levam em consideração a subjetividade. A restrição dá-se por diversas formas. Ocorre, por um lado, antes de tudo, uma indefinição e um desrespeito à metodologia clínica como atividade específica. A clínica perdeu sua especificidade metodológica. Todo clínico (médico, psicólogo etc.) pode, sem restrição ética, metodológica ou epistemológica assim se intitular, ignorando as especificidades dessa atividade. Pesquisa recente revela que há, no Brasil, mais de 5.000 tipos diferentes de psicoterapia. O desafio é, então, voltado para o trabalho de recuperação específica do método. Por outro lado, a clínica se expandiu consideravelmente: deixou de ser praticada somente em hospitais e consultórios particulares e, graças à importante Reforma Psiquiátrica Brasileira e ao Sistema Único de Saúde (SUS), passou a ser uma atividade do Estado.

Será que o rico caráter miscigenado da cultura brasileira não permite uma definição "pura" da clínica? O trabalho de recuperação do método precisa, então, levar em conta essa complexa situação.

A formação de psicanalistas, clínicos que levam em consideração a natureza subjetiva da sua prática, deixou de ser monopólio de sociedades e associações tradicionais de formação, como a International Psychoanalytic Association (IPA) e a miríade institucional lacaniana passou também a ser realizada por outros institutos de formação. Todas essas transformações afastou a clínica da ortodoxia baseada nos escritos e no ensino de Mestres e passou a depender parcialmente da contingência prática. Os trabalhadores de saúde mental, funcionários públicos, perceberam o hiato entre o estudo repetitivo e ortodoxo das teorias e a prática solicitada pela clínica marcada pela singularidade do caso que praticavam no dia a dia. Mas não há espaço na rede de saúde mental para a atividade de pesquisa. A transformação da vivência clínica em uma experiência, atividade socialmente compartilhada, não é possível e frequentemente o trabalhador se perde em atividades formais burocráticas regidas por ideologias políticas imediatistas (Endo, 2013). O psicanalista deixa de ser um iano (freudiano, kleiniano, lacaniano, winnicottiano etc.) sem ter uma referência teórica e desconhece a tradição da clínica.

O ensino da psicanálise na Universidade colabora para esse quadro bastante complexo.

A universidade solicita, além do ensino magistral, a pesquisa científica e os psicólogos clínicos e psicanalistas precisam parar de repetir o que o Mestre diz e precisam se voltar para a investigação que não suporta a ortodoxia magistral (Berlinck, 2013). O ensino magistral, como se sabe, só é possível com a manutenção da relação Mestre/Aluno.

Para que a pesquisa se desenvolva, a relação Mestre/Aluno precisa evoluir para uma relação entre estudantes. Nessa nova orientação, o Mestre se transforma num estudante entre estudantes. É verdade que um estudante mais experimentado nos afazeres da investigação científica. Mas, nessa nova circunstância, não há lugar nem para o Mestre e nem para o aluno: quem pesquisa é estudante. 


\section{EDITORIAL}

É bom lembrar o que quer dizer aluno, pelo menos no Dicionário Houaiss da Lingua Portuguesa:

1. aquele que foi criado e educado por alguém, por mestre ou preceptor; educando 2. Indivíduo que recebe instrução ou educação em estabelecimento de ensino ou não; discípulo, estudante, escolar 3. Pessoa de parco saber em determinada matéria, ciência ou arte e que precisa de orientação e ensino; aprendiz 4. membro de comunidade, corporação etc. 5. indivíduo natural de determinado local (país, região etc.); filho 6. aquele que apresenta insuficiência na função psíquica e lentidão no processo de aprendizado, requerendo o uso de técnicas de ensino adequadas.

Além disso, o Dicionário se refere à etimologia latina da palavra (alumnus) querendo dizer "criança de peito, lactente, menino, aluno, discípulo", derivado do verbo alere "fazer aumentar, crescer, desenvolver, nutrir, alimentar, criar, sustentar, produzir, fortalecer etc.".

Já o mesmo dicionário afirma que estudante é

1. o que frequenta regularmente curso (de ensino fundamental ou médio, universitário etc.) em alguma instituição ou qualquer outro curso livre, no qual se pode adquirir alguma habilidade e/ou conhecimento.

Estudar, por sua vez, refere-se a

aplicar o espírito, a inteligência e a memória para aprender (habilidade, técnica, ciência, arte etc.); adquirir habilidade e/ou conhecimento ... 2. procurar compreender (algo) através da reflexão; meditar, refletir 3. examinar; observar atenta e minuciosamente 4. fixar, por meio da memória; decorar.

Aluno, então, não é estudante ainda que este seja, pelo menos, um pouco aquele.

Aluno é infantil, com pouca vivência e menos experiência, necessitando se apoiar no Mestre. Estudante, por sua vez, possui autonomia porque deixou de ser aluno conseguindo formular uma vivência enigmática e obscura que precisa ser compreendida. Reconhece, assim, que a experiência do Mestre é insuficiente para a compreensão do fenômeno.

O estudante possui, pois, um caso clínico (Magtaz \& Berlinck, 2012), com sua natureza singular, obscura e enigmática que ele leva à pesquisa.

Para ser estudante, o futuro clínico deixa de ser aluno e passa a ter uma vivência. Mas essa prática não pode se transformar numa profissão que não estimula a pesquisa. $\mathrm{O}$ trabalhador precisaria, assim, se transformar num estudante promovendo o avanço do conhecimento científico e o aperfeiçoamento da clínica.

O desafio e a aposta da Psicopatologia Fundamental é, em resumo, a de estimular a pesquisa científica na psicoterapia. 


\section{Bibliografia}

Berlinck, M.T. (2013, out.dez.). O método científico nos primórdios da Universidade: o caso de Andreas Vesalius de Bruxelas. Ensino Superior, 11.

Endo, T.C. (2013). A Saúde Mental à margem do SUS: experiências de vastidão e confinamento nas práticas clínicas. Tese de Doutorado em Psicologia Clínica. Pontifícia Universidade Católica de São Paulo, São Paulo.

Houaiss, A. et al. (2007). Dicionário Houaiss da Língua Portuguesa. Rio de Janeiro: Objetiva.

Magtaz, A.C. \& Berlinck, M.T. (2012, março). O caso clínico como fundamento da pesquisa em Psicopatologia Fundamental. Revista Latinoamericana de Psicopatologia Fundamental, 15(1), 71-81.

Citação/Citation: Berlinck, M.T. (2015, dezembro). Editorial. Missão da Psicopatologia Fundamental. Revista Latinoamericana de Psicopatologia Fundamental, 18(4), 595-598.

Editores do artigo/Editors: Prof. Dr. Manoel Tosta Berlinck e Profa. Dra. Sonia Leite

Recebido/Received: 13.10.2015/ 10.13.2015 Aceito/Accepted: 27.10.2015 / 10.27.2015

Copyright: (C) 2009 Associação Universitária de Pesquisa em Psicopatologia Fundamental/ University Association for Research in Fundamental Psychopathology. Este é um artigo de livre acesso, que permite uso irrestrito, distribuição e reprodução em qualquer meio, desde que $\mathrm{o}$ autor e a fonte sejam citados / This is an open-access article, which permits unrestricted use, distribution, and reproduction in any medium, provided the original authors and sources are credited.

\section{Manoel Tosta Berlinck}

Sociólogo; Psicanalista; Ph.D. pela Universidade de Cornell, Ithaca, N.Y., USA; Professor aposentado da Universidade Estadual de Campinas - Unicamp (Campinas, SP, Br); Professor do Programa de Estudos Pós-Graduados em Psicologia Clínica da Pontifícia Universidade Católica de São Paulo - PUC-SP (São Paulo, SP, Br), onde dirige o Laboratório de Psicopatologia Fundamental; presidente (2002-2014) da Associação Universitária de Pesquisa em Psicopatologia Fundamental, editor de Pulsional Revista de Psicanálise e da Revista Latinoamericana de Psicopatologia Fundamental; Membro da World Association of Medical Editors - WAME (Associação Mundial de Editores de Medicina); Ex-diretor da Livraria Pulsional e da Editora Escuta, autor de diversos livros e numerosos artigos.

Rua Tupi, 397/103

01233-001 São Paulo, SP

e-mail: mtberlin@uol.com.br

This is an open-access article, which permits unrestricted use, distribution, and reproduction in any medium for non-commercial purposes provided the original authors and sources are credited. 